\title{
Perfil longitudinal e a aplicação do índice de gradiente (RDE) no rio dos Patos, bacia hidrográfica do rio Ivaí, PR
}

\author{
Rafaela Harumi Fujita ${ }^{1}$, Priscila Panzarini Gon ${ }^{1}$, Jose Cândido Stevaux ${ }^{1,2}$, \\ Manoel Luiz dos Santos ${ }^{2}$ \& Mario Lincoln Etchebehere ${ }^{3}$
}

\begin{abstract}
Resumo Este artigo apresenta uma análise do perfil longitudinal e da aplicação do índice de gradiente (RDE) no rio dos Patos (bacia hidrográfica do rio Ivaí, PR), com o objetivo de detectar e quantificar zonas anômalas ao longo de seu curso principal que possam identificar atividade neotectônica e/ou imposição litológica. O rio dos Patos tem $127 \mathrm{~km}$ de extensão e amplitude de relevo de $660 \mathrm{~m}$. Em sua maior parte, o canal dos Patos encontra-se desajustado e a ocorrência de um knickpoint, permite sua divisão em dois trechos. A aplicação do índice de gradiente (RDE) e a elaboração do perfil longitudinal possibilitaram a detecção de pontos com gradientes anômalos distribuídos ao longo de sua drenagem. Dos 22 trechos medidos, 8 apresentaram índices de RDE acima de 2. Estes trechos estão distribuídos no alto e baixo curso do rio. No alto curso, observa-se a ocorrência da Formação Serra Geral e os menores valores de RDE, já no baixo curso, onde há predominância da Formação Teresina, encontram-se os maiores valores detectados. As anomalias de $2^{\mathrm{a}}$ ordem estão associadas a mudanças litológicas, lineamentos do relevo e encontro de tributários significativos, como é o caso do rio São João. Já as anomalias de $1^{\mathrm{a}}$ ordem estão vinculadas às diferenças na resistência litológica, associadas a um controle estrutural, o que propicia condições adequadas para formação de cachoeiras.
\end{abstract}

Palavras-chave: Perfil longitudinal, índice de gradiente, bacia hidrográfica do rio Ivaí, rio dos Patos.

\begin{abstract}
Longitudinal profile and application of index gradient in the Patos River, Ivaí River basin, PR. This paper presents the results of the longitudinal profile analysis and the application of gradient index (RDE) in the Patos River, a tributary of the Ivaí River basin, PR. The goal is identify and quantify the anomalous zones along river course concerning their genesis - activity neotectonic or/and lithological imposition. The Patos River has a length of $127 \mathrm{~km}$ and a relief amplitude of $660 \mathrm{~m}$, The occurrence of an important knickpoint in the middle course the Patos River can be divided into two stretches. Of the 22 sections measured, 10 were considered anomalous, distributed in both upper and lower course. In the upper course, over a basaltic bedrock of the Serra Geral Formation the RDE values are lower than those in the lower course, where river flows over sedimentary rocks of the Terezina Formation. The $2^{\text {nd }}$ order anomalies are related to lithological changes, relief alignments and channel confluences - as in the case of São João River. The $1^{\text {st }}$ order anomalies are linked to differences in rock resistance associated with structural control, which provides the formation of waterfalls.
\end{abstract}

Keywords: longitudinal profile, gradient index, Ivaí River basin, Patos River.

INTRODUÇÃo Um curso fluvial é um sistema dinâmico, que pode apresentar ao longo de sua extensão diversos segmentos distintos, com características diferenciadas expressas em seu perfil longitudinal. Normalmente, os rios possuem segmentos em equilíbrio (ajustados) e em desequilíbrios (desajustados). Neste contexto, Carlston (1969) ressalta que os trechos em equilíbrio apresentam inclinações suaves e constantes no perfil longitudinal, já os trechos em desajustes apresentam irregularidades ou mesmo deformações em seu traçado.

O perfil longitudinal de um canal representa um elemento muito importante para o estudo da geomorfologia. Larue (2008) afirma que ele auxilia no entendimento da configuração do sistema fluvial, pois resulta da interação entre a incisão fluvial, a litologia e as trocas no nível de base. Richards (1982) complementa que o perfil longitudinal reflete as influências geológicas, tectônicas e de mudanças de nível de base, além de influenciar nos processos fluviais de erosão e deposição.

Hack (1973) propôs o índice de gradiente (Gradient index - RDE) como um elemento bastante prático para a determinação de "anomalias" significativas na concavidade natural do perfil longitudinal, o que possibilitou a normalização dos valores de gradiente e a identificação de anomalias de drenagem em cada trecho de um curso fluvial. A utilização desse índice permite

1 - Programa de Pós-Graduação em Geociências e Meio Ambiente, Instituto de Geociências e Ciências Exatas, Universidade Estadual Paulista, Rio Claro (SP), Brasil. E-mail: rfharumi@yahoo.com.br, pripg@hotmail.com, josecstevaux@gmail.com

2 - Grupo de Estudos Multidisciplinares do Ambiente - GEMA, Universidade Estadual de Maringá, Maringá (PR), Brasil. E-mail: mldsantos@uem.br

3 - Programa de Pós-Graduação em Análise Ambiental Guarulhos, Universidade de Guarulhos, Guarulhos (SP), Brasil. E-mail: metchebehere@ung.br 
detectar, no perfil longitudinal de um rio, alterações no seu curso, uma vez que relaciona a declividade do canal com a extensão do respectivo trecho, fornecendo assim, um índice para comparação de trechos fluviais de diferentes magnitudes (Martinez 2004).

O perfil longitudinal de um rio pode ser influenciado por diversos fatores, dentre eles: confluência de tributários, variações na resistência à erosão do substrato rochoso, erosão remontante por mudança brusca em nível de base à jusante, ou ainda por deformações neotectônicas locais ou na bacia de drenagem (Acklas Jr. et al. 2003). Para compreender a forma do perfil longitudinal é necessário que seja feito um estudo detalhado, levando em conta a geologia, a evolução morfogenética, bem como o estudo das mudanças na morfologia, sinuosidade e estrutura de fluxo no canal fluvial (Demoulin 1998).

Os métodos empregados neste trabalho, ainda que já conhecidos na literatura, são de grande eficácia para a detecção e quantificação de zonas anômalas dentro de uma bacia ou mesmo para um curso fluvial, como verificaram Etchebehere (2000), Etchebehere et al. (2006) e Martinez (2004) em vários rios de médio porte nos estados de São Paulo e Paraná. Uma vez que os cursos fluviais são elementos muito sensíveis às modificações crustais, constituem-se elementos apropriados para a análise de cunho tectônico, permitindo avaliar quantitativamente as modificações e deformações tectônicas (Etchebehere 2000).

Estudos sobre o perfil longitudinal em rios brasileiros restringem-se a alguns trabalhos no rio do Peixe - SP (Etchebehere 2000), rio Pirapó - PR (Martinez 2004), rio Santo Anastácio (Guedes et al. 2006, Guedes 2008), rio Ivaí (Fujita 2009), Córrego Baiano (Melo et al. 2010), que enfocaram a análise do índice de gradiente (RDE) para a identificação de anomalias em bacias de drenagem para entender a evolução da rede de drenagem e do seu substrato rochoso.

Este trabalho tem como objetivo analisar perfil longitudinal do rio dos Patos através do seu perfil longitudinal e da aplicação do índice de RDE buscando detectar e quantificar zonas anômalas ao longo de seu curso principal que possam identificar atividade neotectônica e/ou imposição litológica.

De acordo com ANA (2007), o estado do Paraná está dividido em duas grandes bacias hidrográficas: a do rio Paraná e a do Atlântico Sul. A área de estudo corresponde à bacia do rio Patos, afluente do rio Ivaí, bacia hidrográfica do rio Paraná entre as latitudes $25^{\circ} 01^{\prime} 03^{\prime \prime} S$ e $25^{\circ} 30^{\prime} 49^{\prime \prime}$ S e longitudes $50^{\circ} 58^{\prime} 18^{\prime \prime} \mathrm{W}$ e $51^{\circ} 08^{\prime} 59^{\prime \prime} \mathrm{W}$ (Fig. 1).

O rio dos Patos nasce no município de Prudentópolis e ao confluir com o rio São João formam o rio Ivaí, um dos principais rios do Estado do Paraná e possui uma extensão de $127 \mathrm{~km}$. Ao longo de sua extensão as altitudes variam de 1.160 a $500 \mathrm{~m}$, representando uma amplitude de $660 \mathrm{~m}$. A bacia hidrográfica do rio dos Patos possui uma alta complexidade litológica, drenando as litologias paleozoicas da Bacia sedimentar do Paraná, dos Grupos Passa Dois e São Bento.
Na área de estudo ocorrem as formações: a) Serra Alta, composta por uma sequência de argilitos, folhelhos e siltitos cinza escuro a preto, apresentando lentes e concreções calcíferas; b) Teresina, composta por uma alternância de argilitos e folhelhos com siltitos e arenitos muito finos cinza claros e com presença de calcários e coquinas; c) Rio do Rastro, caracterizada por siltitos e arenitos finos; d) Botucatu, formada essencialmente por arenitos fino a médio bem selecionados, ressalta-se que devido a falhas, esta formação não ocorre em superfície na bacia; e e) Serra Geral, constituída por basaltos escuros (Schneider et al. 1974) (Fig. 2).

Estruturalmente a área é influenciada pelo alinhamento estrutural e magnético do rio Alonzo, que representa uma área de concentração de anomalias lineares extensas, com larguras variáveis entre 80 e 100 $\mathrm{km}$, as linearidades são representadas por diques de diabásio, mas também por falhas e fraturas com direções preferenciais NW-SW (Fig. 2). O relevo, em geral, possui topos aplainados, vertentes convexas, dissecação média e vales predominantemente em "V". A área de estudo, segundo a classificação de Santos et al., (2006), está localizada na Bacia sedimentar do Paraná, no Segundo Planalto Paranaense e compreende as seguintes subunidades morfoesculturais: Planaltos residuais da Formação Teresina, Planalto de Prudentópolis, Planaltos residuais da Formação Serra Geral, Planalto do Alto Ivaí, Planalto de Pitanga/Ivaiporã.

O clima é subtropical, apresentando temperaturas médias que variam de $13,3^{\circ}$ a $21,6^{\circ} \mathrm{C}$, com pluviosidade média anual de $1.500 \mathrm{~mm}$. A vegetação predominante é a Floresta Ombrófila mista, que corresponde a uma unidade fitoecológica onde se contempla a mistura de representantes das floras tropical e temperada.

MATERIAIS E MÉTODOS Para este estudo, foram elaborados o perfil longitudinal e a análise do índice de gradiente (RDE) para o rio dos Patos, o afluente formador principal do rio Ivaí. Para a confecção do perfil longitudinal foram utilizadas cartas topográficas nas escalas 1:100.000 e 1:50.000 do Exército Nacional e do IBGE e um curvímetro analógico para a coleta das variáveis.

$\mathrm{Na}$ análise do perfil longitudinal utilizou-se a metodologia mencionada por McKeown et al. (1988 apud Etchebehere 2000) baseada na premissa de que todo curso fluvial procura o seu equilíbrio, sofrendo para isso erosão ou agradação em seu próprio leito. A escolha da equação que melhor represente a distribuição dos pares ordenados constitui um ponto vital para a técnica de análise flúvio-morfométrica. O estabelecimento da referida equação é objeto de discussões na literatura pesquisada (e.g. Volkov et al. 1967). Tanner (1971) concluiu, inclusive, que não existiria uma curva completamente satisfatória para todo tipo de perfil, devendo, cada trecho da drenagem, ser representado por sua própria curva, configurando o chamado "perfil composto" no sentido de Shepherd (1985), ou o que Hack (1973) designou como séries conectadas de trechos com diversas extensões, cada um deles com conformação logarítmica. Assim 


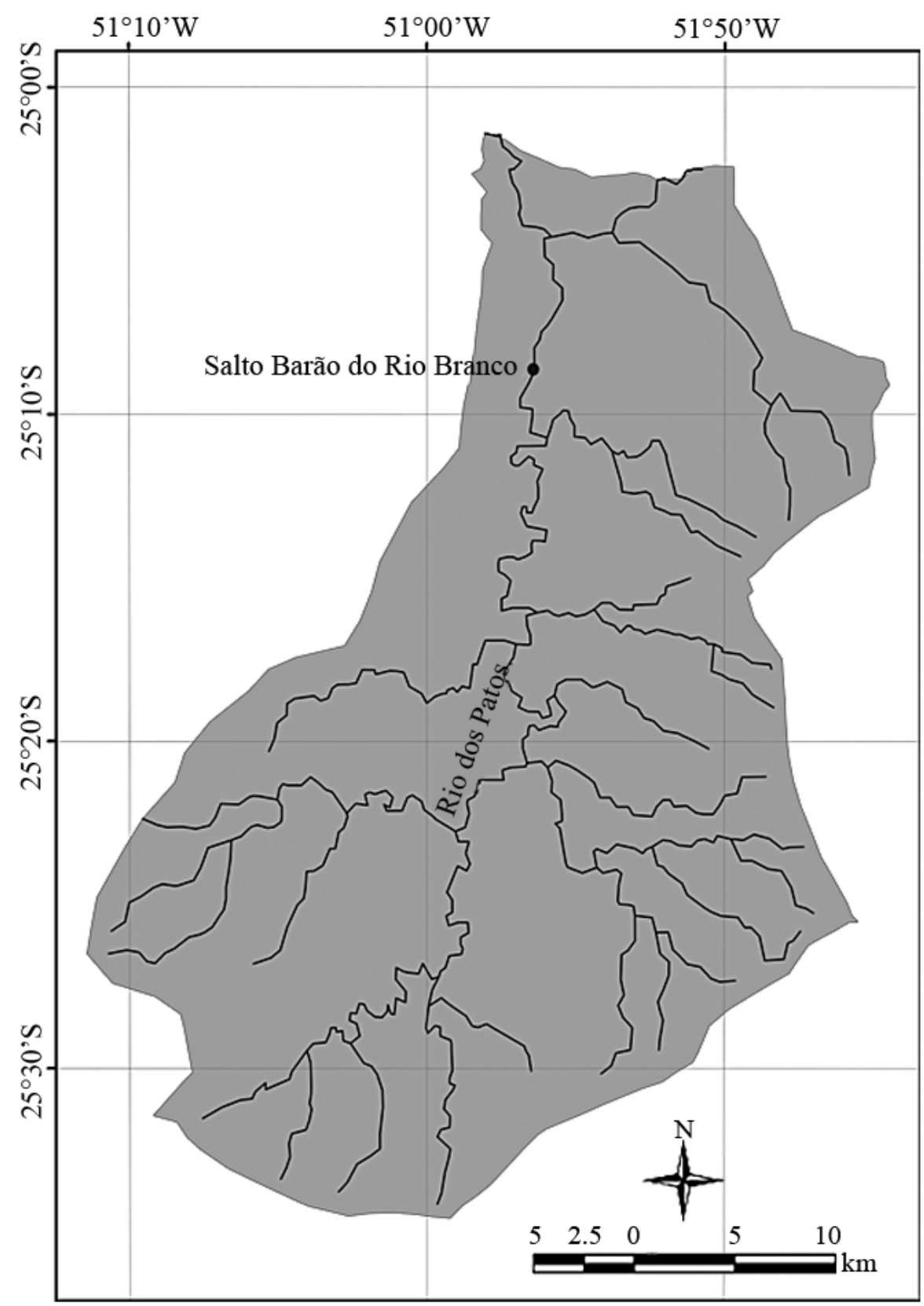

Figura 1 - Bacia hidrográfica do rio dos Patos - mapa de localização.

sendo, buscou-se determinar uma equação e uma linha de melhor ajuste ao perfil, sendo consideradas anomalias os afastamentos superiores a $10 \mathrm{~m}$ dessa linha. Trechos acima da linha de melhor ajuste foram considerados áreas ascendentes (convexos) e abaixo desta, áreas subsidentes (côncavos).

O índice de gradiente (RDE) foi calculado por trecho e em sua totalidade, por meio das equações propostas por Hack (1973):

$$
\begin{aligned}
& \text { RDE trecho }=(\mathrm{DH} / \mathrm{DL}) \times \mathrm{L} \\
& \mathrm{RDE} \text { total }=(\mathrm{DH} / \mathrm{lnL})
\end{aligned}
$$

onde: DH é a amplitude de relevo (diferença altimétrica) entre dois pontos selecionados do curso d’água; DL é o comprimento do trecho analisado; L corresponde à extensão acumulada do rio até o ponto médio do trecho onde o índice RDE está sendo calculado e $\operatorname{lnL}$ é o logaritmo natural do canal.

Nesse estudo foi considerado que os valores de RDE (razão entre RDE trecho/RDE total) abaixo de 2 são considerados trechos em equilíbrio, entre os limiares 2 a 10 são trechos com anomalias de $2^{\text {a }}$ ordem e valores de RDE acima de 10 são trechos com anomalias de $1^{\text {a }}$ ordem, como sugerido por Etchebehere (2000) para o rio do Peixe.

RESULTADOS E DISCUSSÕES Rios em equilíbrio apresentam a curva de seu perfil longitudinal mais ajustada a um modelo teórico (linha de melhor ajuste), não apresentando nenhum processo de ascensão ou 


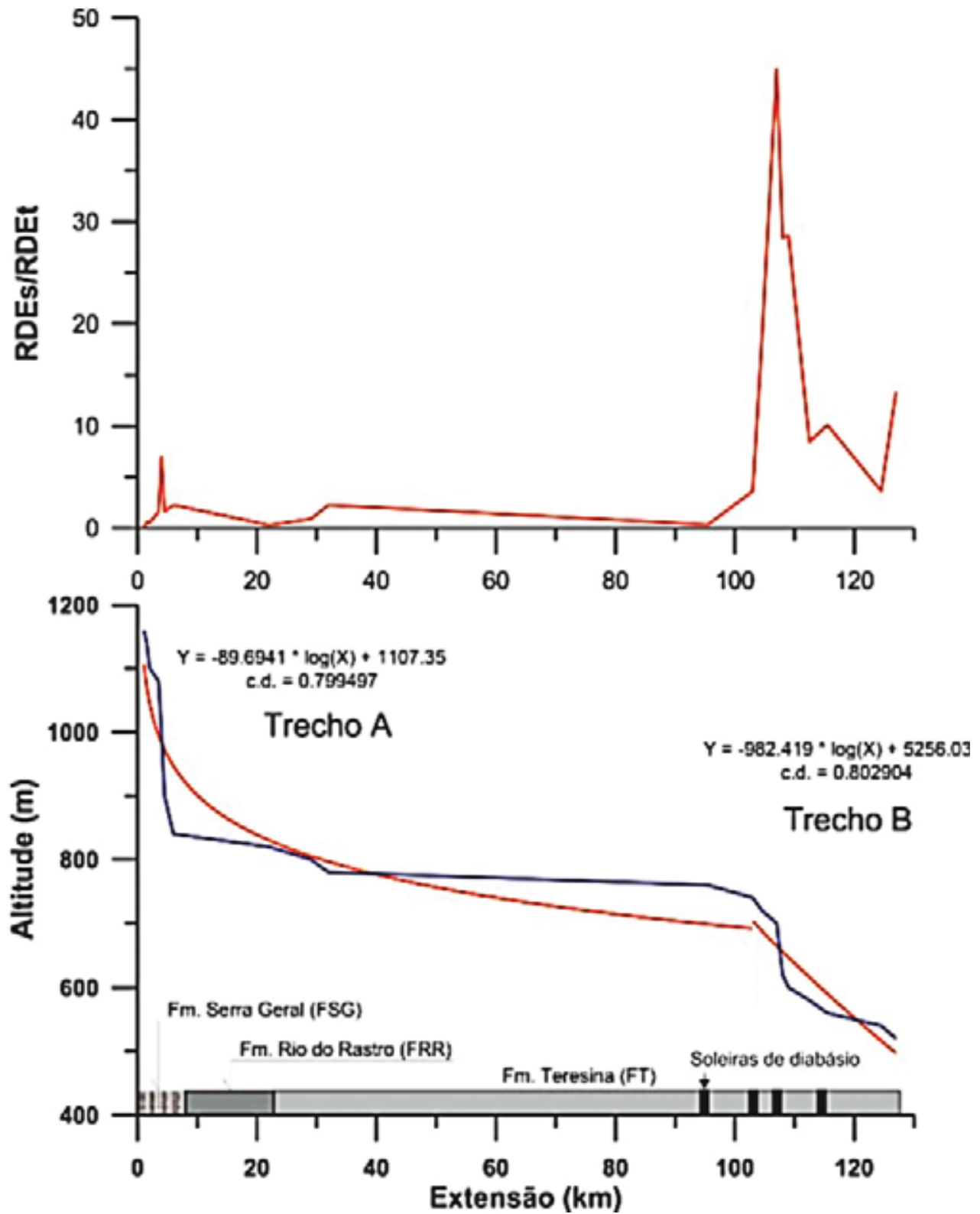

Figura 2 - Perfil longitudinal do rio dos Patos, subdividido em dois principais trechos (A e B) e distribuição dos valores RDEs/RDEt ao longo do referido perfil.

subsidência ao longo de sua extensão. A curva do perfil longitudinal do rio dos Patos encontra-se em sua maior parte desajustada. A figura 2 ilustra o perfil longitudinal do Rio dos Patos e a distribuição dos valores da razão RDEs/RDEt, no caso do perfil, pode-se subdividir o referido curso d’água em dois principais trechos A (no alto curso) B (no baixo curso), separados por aproximadamente $100 \mathrm{~km}$. Este trecho de separação deve corresponder ao que Bjornberg (1969) designou knickpoint, que funcionaria como uma soleira, estabelecendo um nível de base local, que separaria dois segmentos fluviais, ambos tendendo a uma conformação longitudinal logarítmica. Vale ressaltar que os valores RDEs/RDEt foram calculados levando-se em conta um denominador estabelecido para cada trecho.

Considerando que o referido knickpoint encontra-se na Formação Teresina, é possível que existam fácies mais resistentes dessa unidade (e.g. silexitos, calcários silicificados) ou até mesmo intrusões de diabásio que aumentem sobremaneira a resistência da rocha. Levando em conta a presença de conspícuos valores de RDEs/RDEt neste trecho, pode-se suspeitar da presença de falhas. Na figura 3, com base no sombreamento do background topográfico, é notável a presença destacada de feixes de lineamentos EW, NNW e NW, famílias estas que podem refletir os altos valores de RDEs/RDEt.

$\mathrm{O}$ trecho localizado entre as altitudes 820 a 560 m (22 a 112,5 km de extensão) constitui um segmento côncavo que totaliza uma extensão de $90,5 \mathrm{~km}$. Neste intervalo, verificam-se rupturas com desnível de até $120 \mathrm{~m}$, marcada pela presença de corredeiras e saltos, muitos deles aproveitados para a exploração do turismo e para a produção de energia elétrica, como é o caso do salto Barão do Rio Branco. 
Dos 22 segmentos mensurados no rio dos Patos, 14 foram identificados como em equilíbrio, ou seja, apresentaram índices de RDE inferiores a 2, os demais segmentos apresentaram anomalias de $1^{\mathrm{a}}$ e $2^{\mathrm{a}}$ ordem (Tab. 1). Os mais expressivos valores de RDE (anomalias de $1^{\text {a }}$ ordem) foram verificados entre os trechos 15 a 18. Já as anomalias de $2^{\mathrm{a}}$ ordem foram verificadas nos trechos 5, 19, 20 e 22.

A distribuição dos índices de RDE ao longo do rio dos Patos mostra concentrações no alto e baixo curso do rio (Fig. 3). No alto rio dos Patos afloram rochas da Formação Serra Geral, onde se encontram os menores valores de RDE. Ao passar da Formação Serra Geral para a Formação Rio do Rasto há a ocorrência de um trecho anômalo, anomalia de $2^{\mathrm{a}}$ ordem, esta justificada pela mudança litológica.

No baixo curso do rio dos Patos, área que compreende os lamitos arenosos da Formação Terezina, foram detectados os mais altos índices de RDE, isto em decorrência, como já referido anteriormente, da presença de fácies mais resistentes à erosão, associadas a um controle estrutural, marcado pela presença de falhas e fraturas. Estes fatores propiciam o desenvolvimento de soleiras, as quais constituem níveis de base local, o que implica no desenvolvimento de quedas d'água (Bartorelli 1997). Situação como essa do rio dos Patos foi observada também por Etchebehere (2000) para o rio do Peixe, sendo interpretada, essa região de saltos, com anomalias de $1^{\mathrm{a}}$ ordem como uma área tectonicamente ativa. Nesse trecho do rio, também foram detectadas anomalias de $2^{\mathrm{a}}$ ordem associadas a uma subsidência no perfil longitudinal, observadas na região que compreende o encontro do rio dos Patos com o rio São João. Carlston (1969) comenta que irregularidades como estas, descritas, são justificadas pelas mudanças abruptas que ocorrem na carga sedimentar e na vazão, nos cursos fluviais, em região de desembocadura.

O perfil longitudinal e os índices de RDE são sensíveis a mudanças nos cursos fluviais e refletem as influências geológicas, tectônicas e de modificações de nível de base, além de influenciar nos processos fluviais de erosão e deposição (Richards 1982, Etchebehere et al. 2006). Ao se analisar a espacialização das anomalias detectadas, verifica-se que as de $2^{a}$ ordem estão associadas a mudanças litológicas, lineamentos do relevo (presença de falhas e diques) e confluência de rios. Já as anomalias de $1^{\mathrm{a}}$ ordem, detectadas em uma área caracterizada por diversos saltos e cachoeiras, estão associadas a diferenças na resistência litológica, controle estrutural, mas uma possível atividade tectônica.
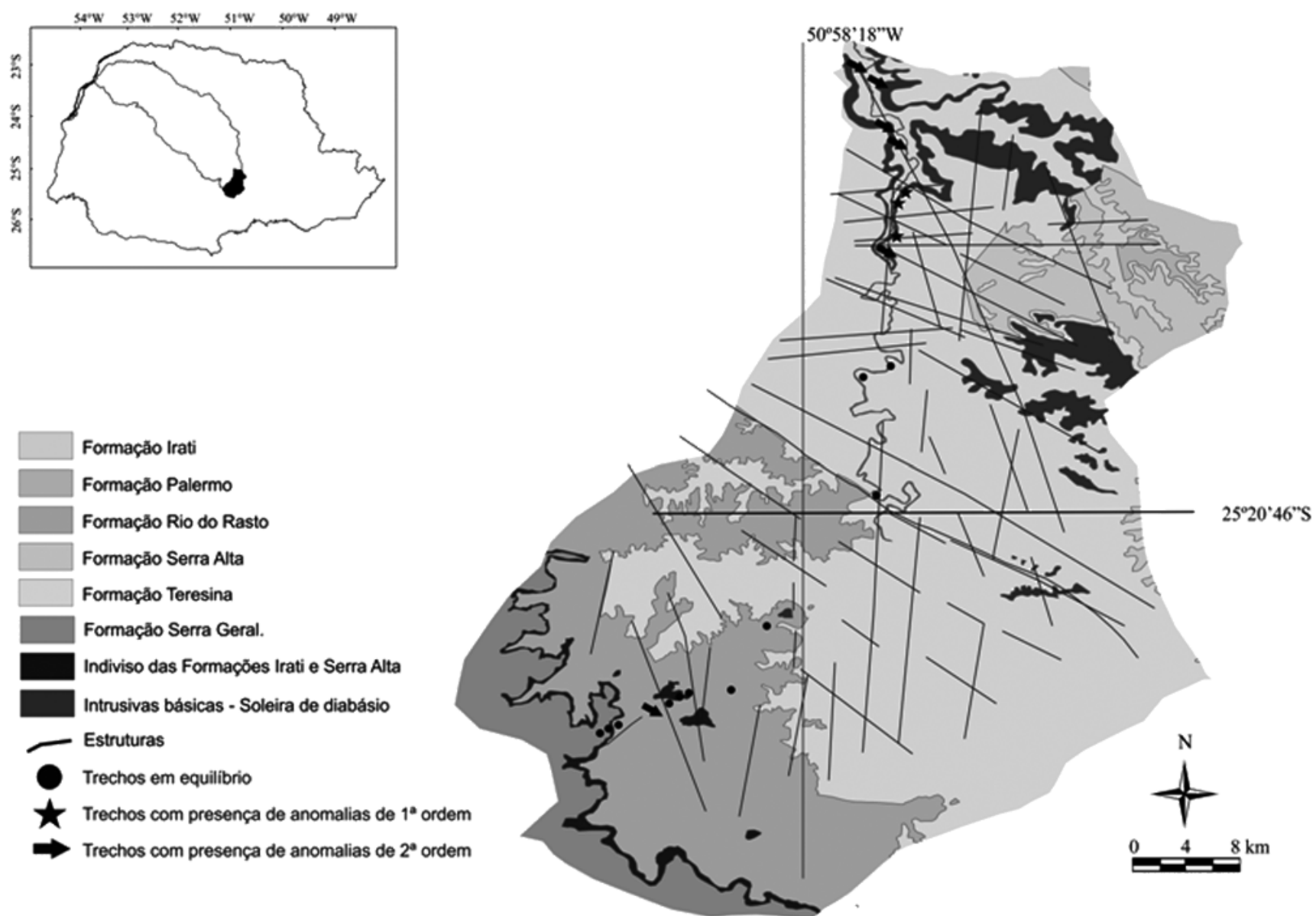

Figura 3 - Mapa geológico da área de estudo com estruturas e trechos medidos ao longo do curso do rio dos Patos. 
Tabela 1 - Resumo das variáveis morfométricas do rio dos Patos. RDE Total = 136,2468. Onde: FSG - Formação Serra Geral, FRR - Formação Rio do Rastro, FT - Formação Teresina.

\begin{tabular}{|c|c|c|c|c|c|c|c|c|c|}
\hline Trecho & $\begin{array}{c}\text { Cota } \\
\text { Superior } \\
\text { (m) }\end{array}$ & $\begin{array}{c}\text { Cota } \\
\text { inferior } \\
(\mathrm{m})\end{array}$ & $\begin{array}{c}\text { Diferença } \\
\text { altimétrica } \\
\text { (m) }\end{array}$ & $\begin{array}{c}\text { Extensão } \\
\text { trecho } \\
(\mathrm{km})\end{array}$ & $\begin{array}{c}\text { Extensão } \\
\text { total } \\
(\mathrm{km})\end{array}$ & Declividade & $\begin{array}{l}\mathrm{RDE} \\
\text { trecho }\end{array}$ & $\begin{array}{c}\text { RDE } \\
\text { Trecho/Total }\end{array}$ & Geologia \\
\hline 1 & 1160 & 1140 & 20 & 1 & 1 & 0,02 & 4 & 0,029053 & FSG \\
\hline 2 & 1140 & 1100 & 40 & 0,5 & 1,5 & 0,08 & 56 & 0,406737 & FSG \\
\hline 3 & 1100 & 1080 & 20 & 0,5 & 2 & 0,04 & 48 & 0,348632 & FSG \\
\hline 4 & 1080 & 1000 & 80 & 1,5 & 3,5 & 0,053333 & 144 & 1,045895 & FSG \\
\hline 5 & 1000 & 900 & 100 & 0,5 & 4 & 0,2 & 640 & 4,648423 & FRR \\
\hline 6 & 900 & 880 & 20 & 0,5 & 4,5 & 0,04 & 148 & 1,074948 & FRR \\
\hline 7 & 880 & 860 & 20 & 0,5 & 5 & 0,04 & 168 & 1,220211 & FRR \\
\hline 8 & 860 & 840 & 20 & 0,5 & 5,5 & 0,04 & 188 & 1,365474 & FRR \\
\hline 9 & 840 & 820 & 20 & 0,5 & 6 & 0,04 & 208 & 1,510738 & FRR \\
\hline 10 & 820 & 800 & 20 & 16 & 22 & 0,00125 & 26,5 & 0,192474 & FRR \\
\hline 11 & 800 & 780 & 20 & 7 & 29 & 0,002857 & 80,57143 & 0,585203 & FT \\
\hline 12 & 780 & 760 & 20 & 3 & 32 & 0,006667 & 208 & 1,510738 & FT \\
\hline 13 & 760 & 740 & 20 & 63,5 & 95,5 & 0,000315 & 29,82677 & 0,216637 & FT \\
\hline 14 & 740 & 720 & 20 & 7,5 & 103 & 0,002667 & 272,5333 & 1,979454 & FT \\
\hline 15 & 720 & 700 & 20 & 1,5 & 104,5 & 0,013333 & 1382,667 & 10,04253 & FT \\
\hline 16 & 700 & 620 & 80 & 2,5 & 107 & 0,032 & 3398,4 & 24,68313 & FT \\
\hline 17 & 620 & 600 & 20 & 1 & 108 & 0,02 & 2144 & 15,57222 & FT \\
\hline 18 & 600 & 580 & 20 & 1 & 109 & 0,02 & 2164 & 15,71748 & FT \\
\hline 19 & 580 & 560 & 20 & 3,5 & 112,5 & 0,005714 & 638,2857 & 4,635972 & FT \\
\hline 20 & 560 & 540 & 20 & 3 & 115,5 & 0,006667 & 764,6667 & 5,553898 & FT \\
\hline 21 & 540 & 520 & 20 & 9 & 124,5 & 0,002222 & 274,8889 & 1,996562 & FT \\
\hline 22 & 520 & 500 & 20 & 2,5 & 127 & 0,008 & 1009,6 & 7,332888 & FT \\
\hline
\end{tabular}

CONSIDERAÇÕES FINAIS Os resultados deste estudo foram obtidos a partir da análise do estudo do perfil longitudinal e da integração do índice de RDE realizadas ao longo do rio dos Patos. Diante dos resultados apresentados, puderam-se chegar às seguintes conclusões:

- em relação ao índice de gradiente (RDE) e estudo dos perfis longitudinais foi possível detectar e quantificar zonas anômalas ao longo do rio dos Patos;

- o rio dos Patos possui uma extensão de $127 \mathrm{~km}$. Ao longo de sua extensão ocorrem dois trechos anômalos: A, no alto curso, e B, no baixo curso, separados por uma soleira considerada como nível de base local;

- foram identificados 14 trechos em equilíbrio e
8 com presença de anomalias (4 com anomalias de $1^{\mathrm{a}}$ ordem e 4 com anomalias de $2^{\mathrm{a}}$ ordem);

- anomalias de $2^{\mathrm{a}}$ ordem no rio dos Patos estão associadas a mudanças litológicas, lineamentos no relevo e encontro de canais fluviais;

- anomalias de $1^{\mathrm{a}}$ ordem são condicionadas por diferenças na resistência litológica associadas a um controle estrutural, marcado pelas suspeitas de presença de falhas, as quais, possivelmente, refletem os altos valores de RDEs/RDEt;

- as anomalias de $1^{\text {a }}$ ordem foram detectadas em região compreendida por saltos e cachoeiras, no baixo curso do rio dos Patos. Essa região remete a uma área influenciada por atividade tectônica.

\section{Referências}

Acklas Jr. R., Etchebehere M.L.C., Casado F.C. 2003. Análise de perfis longitudinais de drenagens do município de Guarulhos para a detecção de deformações neotectônicas. Revista UnG - Geociências, 8(6):64-78.

ANA-AGÊNCIA NACIONAL DE ÁGUAS. 2007. Geo Brasil - Recursos Hídricos. Brasília, Resumo Executivo, 60 p.

Bartorelli A. 1997. As principais cachoeiras da Bacia do Paraná e sua relação com alinhamentos tectônicos. Tese de Doutorado, Instituto de Geociências e Ciências
Exatas, Universidade Estadual Paulista, Rio Claro, 200 p. Bjornberg A.J.S. 1969. Contribuição ao estudo do Cenozóico paulista: tectônica e sedimentologia. Tese Concurso para cargo de Professor, Universidade de São Paulo, São Carlos, $128 \mathrm{p}$.

Carlston C.W. 1969. Longitudinal slope characteristics of rivers of the mid-continent and the Atlantic east Gulf slopes. International Association of Scientific Hydrology Bulletin, 14(4):21-31 [doi:10.1080/02626666909493751]. 
Demoulin A. 1998. Testing the tectonic significance of some parameters of longitudinal river profiles: the case of the Ardenne (Belgium, NW Europe). Geomorphology, 24:189-208.

Etchebehere M.L.C. 2000. Terraços neo-quaternários no vale do rio do Peixe, planalto ocidental paulista: Implicações estratigráficas e tectônicas. Tese de Doutorado, Instituto de Geociencias e Ciências Exatas, Universidade Estadual Paulista, Rio Claro, 336 p.

Etchebehere M.L.C., Saad A.R., Santoni G.C., Casado F.C., Fulfaro V.J. 2006. Detecção de prováveis deformações neotectônicas no vale do rio do Peixe, região ocidental paulista, mediante aplicação do índice RDE (relação declividade extensão) em segmentos de drenagem. Geociências, 25:271-279.

Fujita R.H. 2009. O perfil longitudinal do rio Ivaí e sua relação com a dinâmica de fluxos Maringá. Dissertação de Mestrado, Departamento de Geografia, Universidade Estadual de Maringá, Maringá, 118 p.

Guedes I.C. 2008. Aplicação de análise flúvio-morfométrica na bacia hidrográfica do rio Santo Anastácio, SP, para detecção de deformações neotectônicas. Dissertação de Mestrado, Universidade Guarullhos, Guarulhos, 118 p.

Guedes I.C., Santoni G.C., Etchebehere M.L.C., Stevaux J.C., Morales N., Saad A.C. 2006. Análise de perfis longitudinais de drenagens da bacia do rio Santo Inácio (SP) para detecção de possíveis deformações neotectônicas. Revista UnG - Geociências, 5(1):75-102.

Hack J.T. 1973. Stream-profile analysis and stream-gradient index. U.S. Geol. Survey Jour. Research, 1(4):421-429.

Larue J.P. 2008. Effects of tectonics and lithology on long profiles of 16 rivers of the southern Cantral Massif border between and Aude and Orb (France). Geomorphology, 93:343-367.

Martinez M. 2004. Aplicação de parâmetros morfométricos de drenagem na bacia do rio Pirapó: o perfil longitudinal.
Dissertação de Mestrado, Departamento de Geografia, Universidade Estadual de Maringá, Maringá, 96 p.

Melo O.A.G., Douhy N., França Jr. P., Santos M.L. 2010. Verificação da influência da imposição litoestrutural sobre a drenagem da bacia hidrográfica do Rio Baiano/ Assis Chateaubriand-PR a partir da aplicação de variáveis morfométricas. Revista Brasileira de Geografia Física, 3:7-13.

Mckeown F.A., Jone-Cecil M., Askew B.L., McGrath M.B. 1988. Analysis of stream-profile data and inferred tectonic activity, Eastern Ozark Mountain region. U.S. Geol. Survey Bull., 1807:1-39.

Richards K.S. 1982. Rivers form and process in alluvial channels. London, Taylor \& Francis, 358 p.

Santos L.J.C., Oka-Fiori C., Canali N.E., Fiori A.P., Silveira C.T., Silva J.M.F., Ross J.L.S. 2006. Mapeamento geomorfológico do estado do Paraná. Rev. Bras. de Geomorfologia, 7(2):3-12.

Schneider R.L., Mülmann H., Tommasi E., Medeiros R.A., Daemon R.F., Nogueira A.A. 1974. Revisão estratigráfica da Bacia do Paraná. In: SBG, Congresso Brasileiro de Geologia, 28, Anais, p. 41-65.

Shepherd R.G. 1985. Regression analysis of river profiles. Journal of Geology, 93:377-384.

Tanner W.F. 1971. The river profiles. Journal of Geology, 79:482-492.

Volkov N.G., Sokolovsky I.L., Subbotin A.I. 1967. Effect of recent crustal movements on the shape of longitudinal profiles and water levels in rivers. In: International Symposium on River Mechanics, 1, Proceedings, p. 105-116.

Manuscrito ID 17887

Submetido em 30 de junho de 2010 Aceito em 21 de dezembro de 2011 